\title{
AS AÇÕES DO GESTOR E SUA CONTRIBUIÇÃO PARA A UTILIZAÇÃO DE RECURSOS LÚDICOS NA EDUCAÇÃO INFANTIL
}

\author{
Simone Oliveira Veras ${ }^{1}$ \\ Liliana Corrêa Rêgo ${ }^{2}$
}

RESUMO: A presente pesquisa surgiu da necessidade de se refletir acerca da importância da utilização do lúdico na Educação Infantil, tendo em vista que este se configura como um tema bastante amplo, possuindo implicações pedagógicas que atingem importantes aspectos referentes ao aprendizado infantil. Nesse sentido, o trabalho problematizou a importância do lúdico como ferramenta pedagógica na Educação Infantil e a contribuição do gestor nesse contexto. As crianças compartilham vivências que envolvem ações voltadas para o seu bem-estar e para a contínua construção de valores primordiais na interação social, como a autonomia e a cooperação. A base teórica sobre o lúdico a partir de uma visão pedagógica, sua importância para a construção do conhecimento e sua utilização no cenário da educação infantil foi sedimentada a partir das contribuições de Friedmann (2012), Lopes (200I), Hoffmann (2012), Sommerhalder e Alves (20II), dentre outros. Sendo assim, a existência de um espaço destinado para brincadeiras e convívio com os outros durante a educação infantil, destacam a interação como um dos eixos mais significativos da aprendizagem nesse segmento escolar.

Palavra-chave: Aprendizagem. Educação infantil. Gestor. Lúdico.

\section{INTRODUÇÃO}

As crianças compartilham vivências que envolvem ações voltadas para o seu bemestar e para a contínua construção de valores primordiais na interação social, como a autonomia e a cooperação. Sendo assim, a existência de um espaço destinado para brincadeiras e convívio com os outros durante a educação infantil, destacam a interação como um dos eixos mais significativos da aprendizagem nesse segmento escolar.

Entender os jogos e brincadeiras como instrumentos favorecedores $\mathrm{da}$ aprendizagem é ter em mente que estes possibilitam de maneira prazerosa aquisição de conhecimentos e, por conseguinte, transformações e mudanças de comportamento. Pode-se afirmar, portanto, que as brincadeiras e os jogos se apresentam como parte integrante do

\footnotetext{
${ }^{1}$ Graduada em Lic. Plena em Pedagogia-UFPI. Especialista em Gestão Educacional com Docência do Ensino Superior-UVA. Mestranda em Educação-FUNIBER UNEATLÂNTICO.

${ }^{2}$ Graduada em Licenciatura Plena em Pedagogia pela UFPI. Especialista em Metodologia do Ensino pela FAESPI. Doutoranda pela FUNIBER-UNINI.
} 
processo pedagógico, ao propiciarem um ambiente motivador para a aprendizagem, ao passo que, caso não se ofereça à criança o contato com o ambiente lúdico, ocorre automaticamente uma recusa dos conhecimentos já adquiridos, já que a criança ao entrar na escola possui muitas experiências que anteriores adquiridas por meio de brincadeiras e jogos que tiveram contato em casa ou em outros ambientes.

A presente pesquisa surgiu da necessidade de se refletir acerca da importância da utilização do lúdico na Educação Infantil, tendo em vista que este se configura como um tema bastante amplo, possuindo implicações pedagógicas que atingem importantes aspectos referentes ao aprendizado infantil. Nesse sentido, o trabalho problematizou a importância do lúdico como ferramenta pedagógica na Educação Infantil e a contribuição do gestor nesse contexto.

Trata-se de pesquisa bibliográfica e de campo, exploratória e descritiva com abordagem qualitativa. Como objetivo geral, buscou-se analisar a importância do lúdico enquanto ferramenta pedagógica na educação infantil da Escola Municipal São José, em Teresina - Piauí e a contribuição do gestor para sua utilização na referida escola. Especificamente, procurou-se identificar as possibilidades do uso do lúdico como facilitador do processo de ensino-aprendizagem de crianças pequenas e os cuidados que devem permear essa prática educativa.

O trabalho ora apresentado encontra-se organizado em introdução, desenvolvimento e conclusão. $O$ desenvolvimento foi dividido em dois tópicos; no primeiro explicitou-se uma discussão teórica sobre o lúdico a partir de uma visão pedagógica, sua importância para a construção do conhecimento e sua utilização no cenário da educação infantil. Contribuíram para a fundamentação teórica estudos de Friedmann (2012), Lopes (200I), Hoffmann (2012), Sommerhalder e Alves (2011), dentre outros.

No segundo tópico, analisou-se o papel do gestor na educação infantil e sua contribuição na prática do brincar. Em seguida, discorreu-se sobre os caminhos metodológicos e analisou-se os dados segmentados pelas teorias que fundamentam esta investigação, analisando o ponto de vista das professoras e da gestora sobre suas práticas alusivas ao uso do lúdico no contexto educativo infantil. Por fim, são apresentadas as considerações finais, que se constituem numa síntese dos conhecimentos construídos no 
decorrer da pesquisa, bem como das constatações, contribuições e recomendações que o trabalho evidenciou.

\section{LUDICIDADE: UM ENFOQUE PEDAGÓGICO}

A educação lúdica sempre esteve presente em todas as épocas, os jogos e brinquedos sempre acompanharam a vida do ser humano. Sommerhalder e Alves afirmam que "são antigos os indícios de existência de brinquedos, brincadeiras e jogos criados e vivenciados pelo homem nas mais diferentes culturas, em todos os cantos do mundo" (20II, p. I2); no entanto, nos dias de hoje a visão sobre o lúdico é diferente, pois sua utilização implica em diferentes objetivos e estratégias.

De acordo com Friedmann (2012), o processo de desenvolvimento da pessoa é investigado de forma criteriosa por Piaget e, em relação ao brincar o estudioso esclarece a importância do mesmo no desenvolvimento intelectual e na evolução dos diferentes estágios infantis. Ainda de acordo com a autora, para entender a visão de Piaget sobre o jogo é necessário conhecer os conceitos de assimilação, onde a criança acrescenta novos estímulos às estruturas cognitivas que já possui e acomodação, onde a criança modifica seu estágio mental em resposta a demandas externas; em alguns momentos esses processos prevalecem uns sobre os outros e em outras vezes se equilibram. Nesse sentido, Piaget afirma que o jogo é:

\footnotetext{
Expressão de uma das fases dessa diferenciação progressiva: é o produto da assimilação, dissociando-se da acomodação antes de se reintegrar nas formas de equilíbrio permanente que dele farão complemento no nível do pensamento operatório ou racional (...) O jogo constitui o polo extremo da assimilação do real ao eu. (PIAGET, 1971, P. 217 APUD FRIEDMANN, 2012, P. 28).
}

Em seus estudos, Friedmann (2012) comenta que, Vygotsky assim como seus seguidores, também tecem considerações bastante construtivas em relação ao brincar, as quais não se distanciam das ideias de Piaget mas sim, as expandem. Para Vygotsky o jogo no universo infantil é um anseio que foi satisfeito e deve ser entendido de forma singular; ele destaca que o jogo é a concretização do imaginário, onde acabam se definindo regras de comportamento que regem as brincadeiras sem que isso seja percebido pelas crianças como uma formalidade necessária ao viver em sociedade. "Enquanto a criança está simplesmente brincando, incorpora valores, conceitos e conteúdos” (LOPES, 20or, p. 36). 
Por meio da brincadeira, a criança envolve-se, sente a necessidade de compartilhar com outro e tem a oportunidade de desenvolver capacidades indispensáveis, como: atenção, afetividade, concentração e outras habilidades psicomotoras, tornando-se participativa e dinâmica. Ao buscar soluções para conflitos surgidos, sua imaginação é desafiada e, consequentemente, sua inteligência e criatividade são estimuladas. A esse respeito, as Diretrizes Curriculares do Município de Teresina para a Educação Infantil (2008, p. 33-34) sugerem:

\footnotetext{
Situações em que as crianças podem brincar: a linguagem, mudando a entonação das palavras, o timbre da voz, o sentido das frases; os objetos, mudando seu uso convencional; os brinquedos, aceitando a imagem que eles propõem ou mudando seus significados e usos; os personagens, pessoas ou animais, mudando sua identidade através da linguagem ou utilizando-se de fantasias e objetos simbólicos; assumindo outras identidades através da manipulação de bonecos, fantoches, marionetes, ouvindo e recontando histórias; os espaços, modificandoos, pintando-os, cobrindo com panos, lençóis; o desenho, desenhando, contando histórias, criando personagens.
}

As brincadeiras são por natureza prazerosas e proporcionam às crianças novas aprendizagens, interações, criam situações de coletividade, trabalho em grupo, elevam o estado de descontração, até mesmo de autonomia e confiança em si mesmo. Outrossim, torna-se evidente o papel da escola em envolver o lúdico em situações de ensino para que as crianças tenham chance de se desenvolverem e se adaptarem à vida em sociedade, uma vez que o jogo permite a abertura de novas perspectivas do uso dos códigos simbólicos. Mas, para que estas ideias se consolidem, é importante compreender os diferentes estágios de desenvolvimento mental infantil e adequar os brinquedos às potencialidades das crianças e, sobretudo, buscar diversificá-los. Nessa perspectiva, Teles (1999, p. 15) afirma que:

A brincadeira, o jogo, o humor colocam o indivíduo em estado criativo. Entretanto, se a brincadeira que estimula a criatividade só pode florescer num ambiente de liberdade e flexibilidade psicológicas, de busca de prazer, de autorealização, devemos concluir que o desenvolvimento daquela encontra-se profundamente vinculado aos objetivos educacionais.

O brincar cria condições para a criança externar suas emoções. "As brincadeiras aprofundam, para a criança a compreensão da realidade, ao mesmo tempo que estimulam a imaginação, condições básicas para se poder ser criativo" (TELES, 1999, p. 15).

No processo da educação infantil o papel da escola é de suma importância e, nela devem existir materiais, espaços para brincadeiras, ou seja, elementos que facilitam a 
mediação da construção do conhecimento. As brincadeiras, conforme já dito, ocupam lugar de extrema importância na educação escolar, pois estimulam a cognição, a coordenação motora, o senso de iniciativa, favorecendo até mesmo o processo de aquisição e progresso da palavra. Através dos jogos e brincadeiras o indivíduo pode, naturalmente, formular hipóteses, explorar sua criatividade, observar e conhecer as pessoas e as coisas ao seu redor.

\section{I A importância do lúdico no contexto escolar}

Pelo simples ato de brincar, a criança tem a possibilidade de desenvolver a confiança em si mesma, sua imaginação, a autoestima, o autocontrole, a cooperação e a criatividade, já que o brinquedo explora o seu mundo interior e a leva ao aprender fazendo. Sátiro (2012) pondera que a educação é um processo contínuo, onde ocorre uma sucessão de acontecimentos éticos, estéticos, epistemológicos e etc. Para a autora é possível aprimorar a qualidade criativa do processo de ensino-aprendizagem posto que a criatividade pode ser manifestada por todos, contribuindo para o desenvolvimento da dimensão lúdica e consciência das coisas.

Segundo Sommerhalder e Alves (2011, p. 12), "Apesar dos inúmeros desencontros entre jogos e educação escolar ao longo da história, não podemos negar que a ligação entre a atividade lúdica e a criança é intensa, o que torna inevitável a presença do jogo no cenário escolar. " Entende-se que um dos objetivos da utilização do lúdico no ambiente escolar é o de auxiliar a criança a obter melhor desempenho no seu processo de ensino-aprendizagem, através da aplicação de uma metodologia espontânea, divertida e recreativa. O lúdico age também como forma de comunicação entre as crianças, possibilitando-lhes aprender de acordo como seu modo de ver o mundo, respeitando suas características e percepções.

A ludicidade presente no contexto escolar, além de contribuir e influenciar na formação da criança, permitindo um enriquecimento permanente, configura-se como uma prática democrática ao tempo em que investe em uma metodologia séria no processo de aquisição do conhecimento. Lopes (200I, p.35) esclarece que "O jogo para a criança é o exercício, é a preparação para a vida adulta. A criança aprende brincando, é o exercício que a faz desenvolver suas potencialidades."

Considerando o que já foi descrito até aqui, ressalta-se dois pontos determinantes e indissociáveis que devem ser apreciados ao se utilizar os jogos e brincadeiras como parte 
integrante do planejamento e do fazer pedagógico; o primeiro é o lúdico no qual a criança sente prazer e satisfação ao brincar, e o outro é o educativo, pois por meio da brincadeira a criança é educada e socializada para a vivência em sociedade, já que o mundo do qual faz parte possui normas, as quais precisam ser conhecidas e praticadas. No entanto, o que se observa muitas vezes no ambiente escolar vai na contramão disso; Sommerhalder e Alves (20II, p. 54), explicam que:

\footnotetext{
Ainda é muito presente nas Instituições de Educação Infantil e, principalmente nas Escolas de Ensino Fundamental, uma cisão, ora explícita ora implícita, entre brincar e estudar, de modo que ao primeiro é concedido direito de existência em hora e lugar determinados, fora dos quais assume ares de transgressão. Haverá o tempo para o sério (a aprendizagem) e o tempo para recreação ressalta Oliveira (2006b), sugerindo uma incompatibilidade entre jogo $e$ a educação institucionalizada na infância.
}

Ademais, o lúdico nas práticas pedagógicas não deve ser visto apenas como descontração, mas como meio para o desenvolvimento e aprimoramento da aprendizagem É importante ressaltar que a motivação do educador escolar para proporcionar a atividade lúdica é fundamental, tendo em vista despertar no aluno o interesse para criar, desenvolver, participar, buscando a construção do conhecimento. A esse respeito Friedmann (2012, p. 46) afirma que "Assumir uma postura lúdica significar aprender e incorporar as linguagens expressivas das crianças e adotar essa postura em todos os conhecimentos e atividades."

A criança quando não brinca, sofre uma série de privações como dificuldades de socialização e comportamento arredio, tornando mais oneroso o processo educativo. Com os jogos e brincadeiras o educador tem em mãos um instrumento transformador de aprendizagens, isto quando utilizado com finalidade adequada; no entanto, para alcançar seus objetivos educacionais torna-se necessário adequá-los aos indivíduos, aos contextos e aos espaços disponíveis, isto é, uma metodologia integrada ao planejamento que construa aprendizagens qualitativamente significativas.

\subsection{O lúdico no cenário da Educação Infantil no Brasil}

O processo de Educação Infantil no Brasil envolve creches e pré-escolas. Esta modalidade escolar passou a integrar a Educação Básica brasileira a partir de 1996, quando a Lei n 9394/96, Lei de Diretrizes e Bases da Educação Brasileira - LDB, entrou em vigor. 
Em relação a Educação Básica e seus níveis de ensino, foi implementada em fevereiro de 2006 a Lei II.274 trazendo algumas modificações na composição dos Arts. 29, 30, 32 e 87 da LDB.

A nova Lei veio regulamentar o Ensino Fundamental de nove anos e estabelecer que, o atendimento às crianças de seis anos de idade passaria a fazer parte do mesmo, assim as crianças dessa faixa etária deveriam ser matriculadas no primeiro ano. Deste modo, à educação infantil caberia o atendimento às crianças de até três anos em creches e de quatro e cinco anos, na pré-escola.

Como o próprio nome já diz, a educação infantil tem como núcleo do seu trabalho as crianças, que gostam e devem brincar e, como forma de garantir tais direitos, a Constituição Federal (Brasil, 1988), em seu Art. 227 assegura que:

É dever da família, da sociedade e do Estado assegurar à criança, ao adolescente e ao jovem, com absoluta prioridade, o direito à vida, à saúde, à alimentação, à educação, ao lazer, à profissionalização, à cultura, à dignidade, ao respeito, à liberdade e à convivência familiar e comunitária, além de colocá-los a salvo de toda forma de negligência, discriminação, exploração, violência, crueldade e opressão (grifo nosso).

O Estatuto da Criança e do Adolescente- ECA (Brasil,199o) no Art. ı6 trata do

direito à liberdade assegurado à criança e ao adolescente, especificando no Inciso IV que entre esses direitos está o “ de brincar, praticar esportes e divertir-se”. Nessa perspectiva, levando em consideração que em uma parte considerável do seu dia a criança está na escola, em respeito e garantia do seu direito de brincar, o espaço escolar configura-se como um dos locais no qual a brincadeira também deve fazer parte, tendo em vista que promovem o desenvolvimento da criança em variados momentos e de diversas maneiras. Como uma das questões presentes para as crianças de faixa etária que integram a Educação Infantil, os Referenciais Curriculares Nacionais para a Educação Infantil- RCNEI (Brasil,1998, vol. oI, p.I3), também apontam a importância do direito de brincar para o desenvolvimento e o aprendizado das mesmas:

Considerando-se as especificidades afetivas, emocionais, sociais e cognitivas das crianças de zero a seis anos, a qualidade das experiências oferecidas que podem contribuir para o exercício da cidadania deve estar embasada nos seguintes princípios:

[...] o direito das crianças a brincar, como forma particular de expressão, pensamento, interação e comunicação infantil [...] 
Em março de 2016 surgiu o Marco Legal da Primeira Infância, que definiu a elaboração e implementação de políticas públicas voltadas para as crianças da faixa etária de zero a seis anos de idade definida portanto, como primeira infância. Na referida lei é possível encontrar nos Arts. 6 e 17 referências quanto à implantação dessas políticas públicas voltadas para a garantia do direito de brincar.

Diante do exposto fica claro que, o reconhecimento conquistado pelo lúdico enquanto prática motivadora de aprendizagens veio para ficar. A ludicidade a que se refere tal afirmação centra-se no contexto escolar que é o cenário principal deste trabalho. De acordo com Hoffmann (2012, p.73);

O cenário da Educação Infantil deve se constituir em um ambiente de brincadeiras, alegre, desafiador, espontâneo, no sentido de favorecer a exploração livre dos objetos, da vivência de situações adequadas ao tempo da criança, no qual ela possa escolher brinquedos ou parceiros, num ritmo próprio, mesmo que diferente de outras, sem pressões ou expectativas dos adultos a serem cumpridas. Nesse espaço, o papel dos professores é o de ampará-las, de conversar com elas, de dar-lhes todo afeto e orientação necessários, organizando e propondo ricas oportunidades de aprendizagem.

Nessa perspectiva, o brincar, enquanto ferramenta pedagógica necessária ao aprendizado da criança da educação infantil deve assumir um eixo norteador, uma postura pedagógica, mas principalmente respeitar seu tempo e seu processo evolutivo; ainda a esse respeito a autora infere (Ibidem, p.72):

Com essa intenção, a observação do professor vai além da rotina, da 'realização ou não' da atividade ou de 'comportamentos apresentados' pelas crianças frente a essas, buscando observar, principalmente, se ele contribuiu para a formação de crianças autônomas, críticas e participativas por meio das brincadeiras, dos conteúdos delineados, dos projetos pedagógicos e outros.

A respeito do lúdico, Vygotsky (1989 apud REDIN et al., 2013) aponta que a criança pequena é imediatista em relação aos seus anseios e, neste ponto o brinquedo responde às essas necessidades. "Nessa fase, surge uma gama de desejos e o brinquedo parece ser inventado quando a criança começa a experimentar desejos não possíveis de realização imediata. Para resolver essa tensão, a criança se envolve em mundo imaginário, o mundo do brinquedo" (Ibidem, p. 8o-8I).

Outrossim, cabe ressaltar que a contribuição do lúdico para o processo de ensinoaprendizagem da criança da educação infantil no contexto escolar depende da visão que o educador possui do mesmo. A esse respeito, as Diretrizes Curriculares do Município de Teresina para a Educação Infantil (2008, p. 33) afirmam que, 
Durante as brincadeiras e jogos o papel de professor deverá ser o de provocar e desafiar a participação coletiva na busca de encaminhamentos e resolução de problemas. É através das brincadeiras ou jogos que podemos despertar e incentivar a criança para o espírito de companheirismo e cooperação.

Com isso, considerando o cotidiano dinâmico das turmas de educação infantil, empregar o lúdico como instrumento de aprendizagem precisa ponderar dois pontos: em primeiro lugar, os jogos e brincadeiras utilizados de forma esporádica para passar o tempo, para "acalmar as crianças" e sem planejamento são totalmente ineficientes; em segundo lugar, os jogos e brincadeiras inseridos dentro de um planejamento, somente têm eficácia quando severamente escolhidos e submetidos a um determinado objetivo educacional previamente definido. Quanto à isso, Redin et al (2013, p. 27): “Acreditamos que qualquer tipo de proposta necessita de uma direção, planejamento, logo para planejarmos, elencamos alguns sinalizadores que poderão servir de pista, sem prescrições, mas que poderão ajudar a pontuar algumas direções (...)”.

Em outras palavras, não é recomendável usar os recursos e atividades lúdicas sem rigoroso e prévio planejamento. Para se alcançar o objetivo educacional é necessário focar as atividades naquilo que se deseja que a criança aprenda. Não se deve classificar o educador pela quantidade de brincadeiras e jogos que ele utiliza, mas sim pela qualidade destes e pela sua preocupação em pesquisá-los e selecioná-los.

\section{A CONTRIBUIÇÃO DO GESTOR ESCOLAR NA PRÁTICA DO BRINCAR}

A instituição de ensino em busca de assegurar o direito infantil de brincar e através de sua prática promover aprendizagens, deve considerar algumas questões como espaço, recursos, metodologia, formação de professores, tudo isso possibilitado através de uma gestão responsável e comprometida com esse público infantil. A educação infantil é a primeira fase do processo escolar; nesta etapa a criança deverá ser acolhida de forma alegre e divertida e a aquisição de recursos lúdicos pela equipe gestora para serem utilizados como metodologia de ensino, é fundamental nessa primeira etapa da vida escolar.

Uma instituição de educação infantil tem como função pedagógica a promoção do desenvolvimento da criança pequena e o gestor deve ter a capacidade de compreender em que consiste essa função; além disso, o mesmo deve conhecer a criança em sua totalidade, o que requer sensibilidade e atenção constante a detalhes de comportamento, com a preocupação de identificar as particularidades de cada criança. Sem esses conhecimentos e 
essas preocupações não é possível construir uma educação infantil que traga uma contribuição efetiva para a construção do conhecimento da criança. A esse respeito, Libâneo, Oliveira e Toschi (2012, p. 499) definem:

É preciso estar claro que a direção e a administração da escola são meios para garantir os objetivos educacionais. Dessa forma, uma escola bem organizada administra com eficiência seus recursos materiais e financeiros, assim como o trabalho de seu pessoal, e emprega processos e procedimentos de gestão, propiciando as condições favoráveis às atividades de ensino-aprendizagem.

O gestor de uma instituição de ensino infantil, em seu papel de líder educacional, deve inspirar e motivar sua equipe a fim de que, no cotidiano escolar, sejam desencadeadas ações propícias à aprendizagem dos alunos de maneira satisfatória. Dialogar, construir objetos, organizar espaços, ler, escrever e discutir sobre os temas ligados ao desenvolvimento infantil são caminhos para que gestor e professores possam interagir em ambientes criativos, em busca de alternativas que possam subsidiar ações voltadas ao desenvolvimento educacional da criança. Quem lida com crianças pequenas que ainda não articulam ideias, pensamentos ou ações de forma coordenada, precisa saber quais cuidados permeiam a prática do ensinar.

A figura de um gestor dinâmico, na busca de uma educação infantil com qualidade, perpassa por propostas pedagógicas mais consistentes, tendo em vista esta etapa configurar-se como primeira fase de ensino, o primeiro contato da criança com o ambiente escolar. Segundo Libâneo, Oliveira e Toschi (2012, p.454-455), "O diretor não pode ater-se apenas às questões administrativas. Como dirigente, cabe-lhe ter uma visão de conjunto e uma atuação que apreenda a escola em seus aspectos pedagógicos, administrativos, financeiros e culturais."

Nota-se a qualidade da instituição de ensino infantil por meio de quem está à frente de sua liderança: o gestor. $O$ mesmo deve perceber a nova identidade que a educação infantil vem experimentando há algum tempo e contribuir para que sua equipe desenvolva seus trabalhos, objetivando levar ao público infantil ações pedagógicas apoiadas em projetos bem estruturados. "O diretor escolar, ao assumir as responsabilidades de seu cargo, assume necessariamente, a responsabilidade de liderar a formação de cultura escolar compatível com a necessária para que o ambiente escolar seja estimulante e adequado para a formação de seus alunos" (LÜCK, 2009, p.irg). 
Destarte o gestor deve oportunizar aos professores e a toda equipe, a participação em formações continuadas, consideradas pela própria natureza do saber e do fazer humano, como práticas que se transformam constantemente, levando-os a desenvolverem ações voltadas para a prática do brincar no meio escolar. Ao liderar e delegar funções, socializando descobertas e procedimentos, cuidando da formação constante da equipe, estimulando a equipe a construir e desenvolver um projeto educativo pedagógico compartilhado, o gestor confirmará a importância do espaço lúdico no meio escolar, oportunizando às crianças, a partir do brinquedo, exercitar a sociabilidade, gerando também o desenvolvimento intelectual, social e emocional das mesmas.

\section{CAMINHO METODOLÓGICO}

A presente pesquisa foi realizada na Escola Municipal São José, situada no Povoado Cantinho Sul, zona rural sul de Teresina-PI, vinculada a Rede Municipal de ensino. A escola pesquisada conta com um total de 122 alunos dispostos em seis salas de aula atendendo aos turnos manhã e tarde, sendo duas turmas de educação infantil: I e II Períodos, totalizando 30 alunos. Para efetivação da pesquisa, contamos com a colaboração de duas professoras da educação infantil, regentes das turmas de I e II Períodos, respectivamente, e da gestora da escola, sendo, portanto, sujeitos representativos e em número significativo para a realização do trabalho. Para preservar a identidade dos sujeitos, estão aqui identificados como $\mathrm{P}_{1}, \mathrm{P}_{2}$ e G, respectivamente.

As professoras e a gestora atuam no exercício da docência em um período que varia entre I a 17 anos. Encontram-se na faixa etária de 28 a 50 anos de idade, possuem curso de nível superior completo em Licenciatura Plena em Pedagogia, todas com pós-graduação. Os dados citados foram obtidos através de aplicação de questionários.

O trabalho realizado quanto aos objetivos, caracteriza-se como uma pesquisa descritiva. Para Gil (2008, p.28), "As pesquisas deste tipo têm como objetivo primordial a descrição das características de determinada população ou fenômeno ou o estabelecimento de relações entre variáveis. " Quanto ao procedimento de coleta utilizado, caracteriza-se como pesquisa de campo e quanto à abordagem do problema, a pesquisa caracteriza-se como qualitativa. Gonsalves (2011, p. 67), define a pesquisa de campo como aquela em que 
“o pesquisador precisa ir ao espaço onde o fenômeno ocorre -ou ocorreu- e reunir um conjunto de informações a serem documentadas”.

Após a aplicação do questionário, as respostas obtidas foram analisadas, interpretadas e comentadas com base na fundamentação teórica utilizada na pesquisa. A análise dos dados esteve sempre relacionada ao tema apresentado no trabalho e à fundamentação teórica do mesmo, de acordo com os objetivos propostos para o estudo.

\section{I Análise e discussão dos dados}

\section{I.r Análise das respostas da gestora}

Ao ser questionada sobre sua visão da importância das brincadeiras, jogos e brinquedos no aprendizado das crianças, a gestora respondeu: "São de grande importância, pois proporcionam ao educador a possibilidade de avaliar as diferentes formas de abstração da aprendizagem dos educandos”.

Nota-se que a gestora percebe o lúdico também como ferramenta de suporte essencial ao acompanhamento do desenvolvimento criança, a esse comentário é necessário acrescentar a visão de Hoffman (2012, p.126),

[...] Nada mais natural, por exemplo, que o olhar do professor se detenha ora numa criança, ora num grupo, ou que, em alguns momentos, esteja observando duas crianças jogando e reflita sobre processos de classificação, seriação ou construção do número durante o jogo e, paralelamente, esteja analisando a forma como duas crianças resolvem uma briga ou uma disputa por brinquedos.

Questionou-se também como a gestora definiria a brincadeira, jogos e brinquedos e a proposta da escola nesse particular. Para ela, a brincadeira "É uma forma de tornar a aprendizagem prazerosa e eficaz, a escola já fez aquisição de alguns jogos, mas percebo que os educadores devem passar por capacitação para que possam planejar atividades que dê [sic.] maior valor à aprendizagem".

Em relação a definição da brincadeira pela fala da gestora, é importante citar que o RCNEI (BRASIL, 1998, p.63) destaca que brincar para a criança é essencial, pois ela expressa "emoções, sentimentos, pensamentos", desejos e necessidades; já em relação à proposta apresentada pela escola a gestora não foi clara, e ainda demonstrou desconhecimento com a forma de utilização dos recursos lúdicos pelas professoras. $\mathrm{O}$ gestor escolar que tem o compromisso com sua escola deve atentar-se às necessidades da 
mesma e assim disponibilizar qualidade e quantidade de recursos pedagógicos, buscar parcerias para sua escola, estimular a participação da comunidade em atividades escolares, promover e/ou incentivar seus professores a buscarem formações continuadas e aos demais funcionários capacitações, tudo isso para promover a qualidade das práticas escolares sempre tão dinâmicas.

A pergunta seguinte abordou a visão da gestora acerca do uso das atividades lúdicas no processo de desenvolvimento cognitivo, afetivo, emocional e social das crianças. De acordo com ela: "As atividades lúdicas ajudam o educando a se desenvolver como um todo e também um ser para os outros, capaz de assimilar o conhecimento e ser capaz de socializar, ajudando os outros a crescerem como seres completos”.

No RCNEI (Ibidem, p. 24), observa-se que "a base do cuidado humano é compreender como ajudar o outro a se desenvolver como ser humano. Cuidar significa valorizar e ajudar a desenvolver capacidades". Sabe-se que na escola o aluno desenvolve habilidades e se desenvolve como humano, como afirmou o texto acima citado, por isso, entende-se a importância da fala da gestora ao destacar o lúdico como elemento capaz de promover mudanças de comportamento e aquisição de novos conhecimentos.

Por fim, perguntou-se como a gestora no desempenho da sua função, contribuía para a utilização de recursos lúdicos enquanto ferramenta pedagógica. A resposta obtida foi: "Creio que preciso aprofundar mais os estudos em relação a estas atividades para que possa ampliar e motivar a equipe pedagógica a trabalhar melhor a temática, mas creio que a equipe já trabalha com algumas atividades que são louváveis”.

Nesta fala, a gestora admite certo desconhecimento a respeito da ferramenta lúdica e do trabalho efetivo da equipe docente com o uso do mesmo como instrumento pedagógico e não esclarece sua contribuição em relação ao mesmo. De acordo com Lück (2012) o diretor escolar precisa ter a dimensão de seu trabalho e não somente carregar o título de gestor. Essa visão passa pelas competências necessárias o trabalho do gestor que, enquanto líder na escola deve possuí-las e desenvolvê-las cabendo ao mesmo autoavaliar suas ações no sentido de realizar um trabalho efetivo na escola. Nesse caso pode-se dizer que, a gestora em questão está em processo de "construção de função", tendo como ponto positivo o fato de perceber suas limitações e a pretensão de saná-las. 


\subsubsection{Análise das respostas das professoras}

Depois de responder sobre sua formação profissional e tempo em que atuam na educação infantil, as professoras $\mathrm{P}_{\mathrm{r}}$ e $\mathrm{P}_{2}$ foram indagadas sobre qual era, em suas óticas, a importância de jogos e brincadeira na educação escolar das crianças. Pergunta para a qual se obteve as seguintes respostas: "É muito importante, pois a criança aprende brincando. Não fica um ensino tão monótono" ( $\mathrm{P}_{\mathrm{I}}$; “ "A ludicidade experimentada nos jogos é como um treino para vivências de situações reais na fase adulta, onde algumas habilidades exigidas estão presentes no momento do brincar" $\left(\mathrm{P}_{2}\right)$.

Diante da fala das professoras, percebe-se que as mesmas associam o lúdico à aprendizagem da criança, para elas, o lúdico pode ser visto como parte integrante de uma proposta metodológica, por proporcionar um ensino prazeroso e dinâmico. No entanto, a professora $\mathrm{P}_{2}$ salienta a relação que existe entre o lúdico e o cotidiano e destaca também que nessa fase a criança constrói conceitos brincando, os quais a levarão a apropriar-se de conhecimentos que serão utilizados na vida adulta. É importante citar o disposto no RCNEI (BRASIL, I998, p.27):

Para brincar é preciso apropriar-se de elementos da realidade imediata de tal forma a atribuir-lhes novos significados. Essa peculiaridade da brincadeira ocorre por meio da articulação entre a imaginação e a imitação da realidade. Toda brincadeira é uma imitação transformada, no plano das emoções e das ideias, de uma realidade anteriormente vivenciada.

Indagadas sobre o uso em sala de aula de brinquedos e brincadeiras e sobre o tempo disponível para as crianças brincarem, as respostas foram: "Sim, utilizo. Geralmente em dias de sexta-feira, que é dia de recreação" (PI); "Utilizo os jogos principalmente na volta do recreio, quando o nível de atenção é menor, então os jogos estão como atrativo para o momento em sala de aula" $\left(\mathrm{P}_{2}\right)$.

É preciso lembrar de acordo com o RCNEI (BRASIL, 1998), que é o professor quem deve administrar o tempo das atividades, não podendo as crianças ficarem sem um direcionamento. $\mathrm{Na}$ fala das professoras percebe-se que não há uma orientação das atividades, e que as mesmas parecem ser usadas como "momentos de descontração", assim sendo, tais atividades podem não contribuir efetivamente para o desenvolvimento das crianças. 
A questão posterior abordou quais as brincadeiras preferidas pelas crianças. De acordo com as professoras: "Correr, pega-pega, dançar, jogos de caça-palavras, quebracabeça, dominós de palavras e alfabeto móvel." ( $\mathrm{PI}_{\mathrm{I}}$; “A dama e o jogo da velha são os mais conhecidos socialmente, mas comumente disponibilizamos jogos de formação de pares de rimas e formação de palavras que são bem aceitos." $\left(\mathrm{P}_{2}\right)$.

As respostas indicam que todas as brincadeiras são bem-vindas pelas crianças, no entanto, é preciso novamente ressaltar a necessidade de se ter um planejamento, pois mesmo com atividades lúdicas, como jogos e brincadeiras, o professor tem que estabelecer critérios e segui-los, pois essas atividades também "são instrumentos essenciais para a reflexão sobre a prática direta com as crianças" (Ibidem, p. 4I).

Por último, foi perguntado sobre qual o objetivo de propor jogos e brincadeiras nessa faixa de idade, ao que as respondentes esclareceram: "Estimular o cognitivo das crianças, ampliando para a aceitação de regras e normas, companheirismo, independência e autoestima." ( $\mathrm{PI})$; “Experimentar habilidades exigidas no mundo adulto como: concentração, objetividade, atenção, organização, memorização e outros. ” ( $\left.\mathrm{P}_{2}\right)$.

Ressalta o RCNEI (Ibidem, p. 30) em relação à organização do ambiente educativo, ser necessário que o professor considere "a interação com crianças da mesma idade e de idades diferentes em situações diversas como fator de promoção da aprendizagem e do desenvolvimento e da capacidade de relacionar-se." Nas respostas das docentes, observa-se que os ambientes e as situações de aprendizagem que envolvem o lúdico são reconhecidas; elas entendem serem estes motivadores de atitudes positivas, como as citadas pelas educadoras.

\section{CONSIDERAÇÕES FINAIS}

Ao se definir o gestor de uma instituição de ensino sobretudo em escolas de educação Infantil onde a primeira infância tem um caráter formador, é preciso levar em consideração não somente a competência de conduzir a parte administrativa, financeira e física da instituição, mas deixar claro que juntamente com o trabalho do mesmo, deve existir o compromisso com o desenvolvimento da criança e na formação dos professores que integram a equipe docente. 
Ao longo deste trabalho, buscou-se levantar questões relevantes às ações do gestor $\mathrm{e}$ sua contribuição para a utilização de recursos lúdicos na educação infantil. Ao mesmo tempo traçou-se uma discussão a respeito da importância das atividades que envolvam jogos e brincadeiras na educação infantil, considerando que a criança consegue através do lúdico adquirir aprendizagens, ainda que partam de situações imaginárias.

A partir da análise das respostas dos sujeitos da pesquisa, ficou nítida a valorização dessas atividades, tanto por parte da gestora, como das professoras. Todavia, é um pouco preocupante a questão da falta de compreensão sobre a orientação das atividades que envolvam jogos e brincadeiras. Percebeu-se ainda que, apesar da falta de conhecimento aprofundado da gestora em relação ao lúdico como recurso pedagógico, a mesma reconhece a importância de atividades deste tipo para que façam parte do planejamento diário e a resistência à utilização do lúdico não é um fator presente na instituição, o que facilita ação das professoras e o aproveitamento das crianças.

Em resumo, finaliza-se ressaltando mais uma vez a importância do uso de atividades lúdicas enquanto metodologia pedagógica que, associado a uma gestão participativa e consciente da importância de se trabalhar com o público infantil através de inúmeras possibilidades, sempre atentando às práticas pedagógica de seus professores, à garantia de recursos e infraestrutura adequados, é capaz de necessidades essências das crianças na primeira infância, tendo em vista que atividades lúdicas comprovadamente fazem parte do processo de aprendizagem.

Acredita-se que o presente trabalho conseguiu analisar o tema proposto e assim contribuir para a melhoria da qualidade da educação infantil, haja vista que suscitará mais discussões e reflexões acerca da temática abordada; sendo assim, indica-se o mesmo não somente aos profissionais da educação, mas a todos aqueles que desejem aprofundar-se sobre o tema.

\section{REFERÊNCIAS}

BRASIL. Estatuto da Criança e do Adolescente. - 4. ed. - Brasília, DF: Senado Federal, Coordenação de Edições Técnicas, 2020.II8 p.

BRASIL. Referencial Curricular Nacional para a Educação Infantil. Ministério da Educação e do Desporto, Secretaria de Educação Fundamental. Brasília, MEC/SEF, 1998. 
FRIEDMANN. Adriana. O brincar na Educação Infantil: observação, adequação e inclusão. I. Ed. São Paulo: Moderna, 2012. 175 p.

GIL, Antônio Carlos. Como elaborar projetos de pesquisa. 4.ed. São Paulo: Atlas, 2008. i76 p.

GONSALVES, Elisa Pereira. Conversas sobre iniciação à pesquisa científica. 5. ed. Campinas, SP. Editora Alínea, 200r. 8o p.

HOFFMANN, Jussara; Avaliação e Educação Infantil: um olhar sensível e reflexivo sobre a criança.18. ed. Porto Alegre: Mediação, 2012. (Edição ampliada e atualizada) is2 p.

LIBÂNEO, J. C.; OLIVEIRA. J. F.; TOSCHI. M.S. Educação escolar, políticas, estruturas e organizações. Io ed. São Paulo: Cortez, 2012. (Coleção docência em formação: saberes pedagógicos / coordenação Selma Garrido Pimenta).

LOPES. Maria da Glória. Jogos na Educação: criar, fazer, jogar. 4. ed. rev. São Paulo. Cortez, 200I.16o p.

LÜCK. Heloísa. Dimensões da gestão escolar e suas competências. Curitiba. Editora Positivo, 2009. $144 \mathrm{p}$.

RÊEGO, L. C., \& Campos, M. A. S. e. (2021). A INFLUÊNCIA DA AUTOESTIMA NO PROCESSO ENSINO-APRENDIZAGEM DE CRIANÇAS NOS ANOS INICIAIS DO ENSINO BÁSICO DAS ESCOLAS MUNICIPAIS DE TERESINA PIAUÍ. Revista Ibero-Americana De Humanidades, Ciências E Educação, 7(II), 924-942. https://doi.org/ro.5189I/rease.v7iri.3124

REDIN, Marita Martins et al. Planejamento, práticas e projetos na Educação Infantil. 2. ed. Porto Alegre: Mediação, 2013. 208 p.

São Paulo: Saraiva, 1996. BRASIL. Lei de Diretrizes e Bases da Educação Nacional, LDB. 9394/1996.

SOMMERHALDER. Aline. ALVES. Fernando Donizete. Jogo e Educação na Infância: muito prazer em aprender. I. ed. Curitiba, PR, 2011. 123 p.

TELES. Maria Luiza Silveira. Socorro! É proibido brincar! Petrópolis, RJ; Vozes, 1997. 72 p.

TERESINA (PI). Secretaria Municipal de Educação. Diretrizes Curriculares do Município de Teresina. Teresina: Halley, 2008. 